\title{
OBSTRUCTION OF THE LUMEN OF NEW ENDOTRACHEAL TUBES
}

\section{F. A. WaLton, M.D.}

ThE IlLUSTRATIONs are pictures of a new Number 10 cuffed oral endotracheal tube. It was placed in the trachea of a completely relaxed man, and there was practically complete obstruction of the airway. Another tube was inspected and found to contain the same rubbery material. This material appears to be latex.
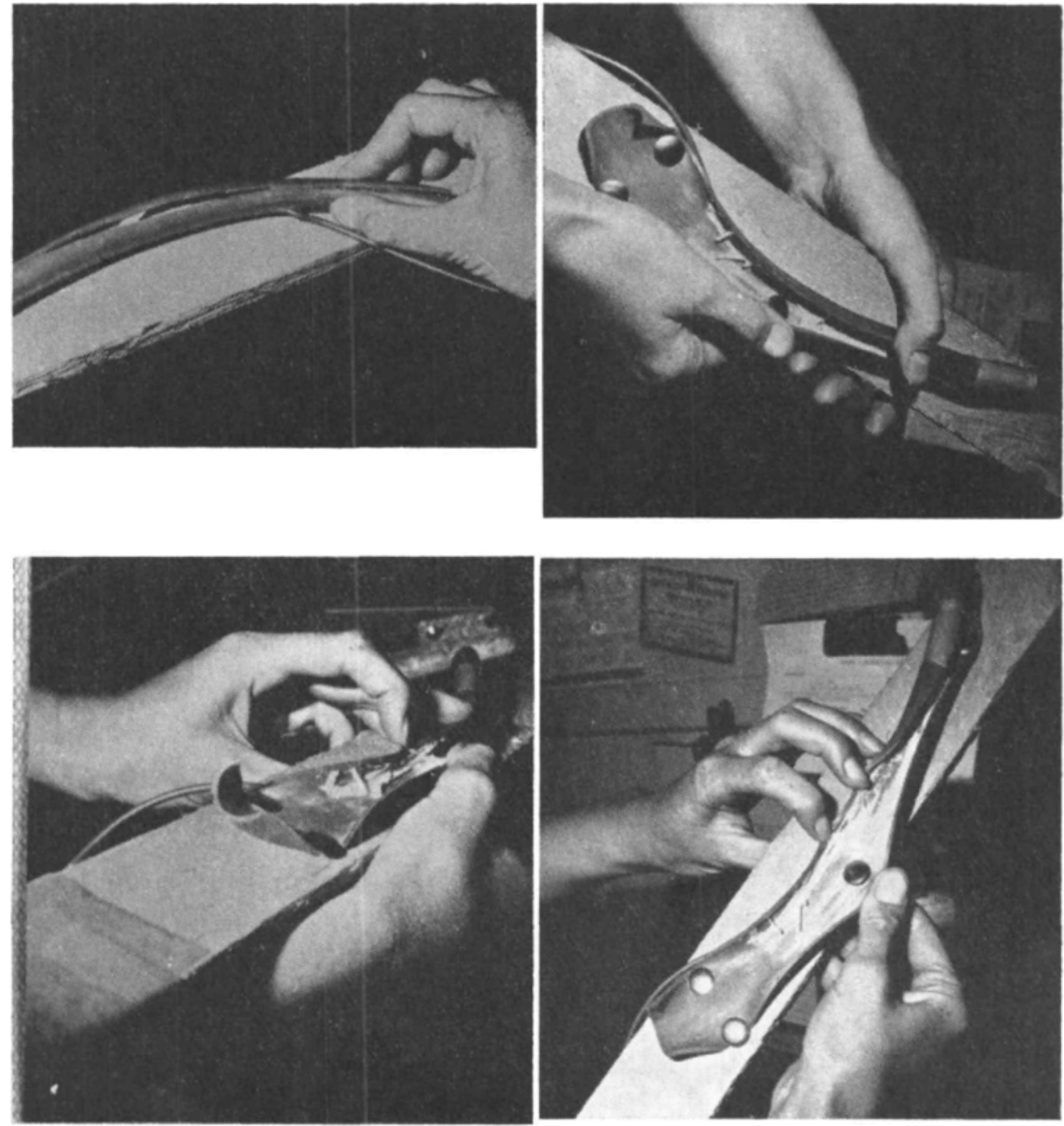

Figures 1-4 
The tubes are dipped in latex during manufacture. Conceivably pieces might become loose and so be aspirated. It should be emphasized that the lumen of all endotracheal tubes should be examined for patency before use.

\section{RÉSUMÉ}

Les photos ci-contre montrent un tube endotrachéal à ballonet, un tube neuf No. 10 oral. Ce tube a été placé dans la trachée d'un homme complètement paralysé et l'on a constaté une obstruction presque complète des voies respiratoires. Nous avons examiné un autre tube et avons trouvé dans sa lumière le même matériel caoutchouté. Ce matériel nous a paru être du latex. Au cours de la fabrication, les tubes sont plongés dans du latex. Nous imaginons que des pièces peuvent s'user et le latex être aspiré. Nous insistons sur la nécessité de vérifier la perméabilité de la lumière de tous les tubes avant de s'en servir. 